\title{
On Acoustic Source Specification for Rotor-Stator Interaction Noise Prediction
}

\author{
Douglas M. Nark* \\ NASA Langley Research Center, Hampton, VA 23681-2199, U.S.A \\ Edmane Envia ${ }^{\dagger}$ \\ NASA Glenn Research Center, Cleveland, OH 44135, U.S.A \\ and Casey L. Burley \\ NASA Langley Research Center, Hampton, VA 23681-2199, U.S.A
}

\begin{abstract}
This paper describes the use of measured source data to assess the effects of acoustic source specification on rotor-stator interaction noise predictions. Specifically, the acoustic propagation and radiation portions of a recently developed coupled computational approach are used to predict tonal rotor-stator interaction noise from a benchmark configuration. In addition to the use of full measured data, randomization of source mode relative phases is also considered for specification of the acoustic source within the computational approach. Comparisons with sideline noise measurements are performed to investigate the effects of various source descriptions on both inlet and exhaust predictions. The inclusion of additional modal source content is shown to have a much greater influence on the inlet results. Reasonable agreement between predicted and measured levels is achieved for the inlet, as well as the exhaust when shear layer effects are taken into account. For the number of trials considered, phase randomized predictions follow statistical distributions similar to those found in previous statistical source investigations. The shape of the predicted directivity pattern relative to measurements also improved with phase randomization, having predicted levels generally within one standard deviation of the measured levels.
\end{abstract}

\section{Introduction}

Increasing air traffic and more stringent aircraft noise regulations continue to expand requirements on community noise prediction capabilities for conventional and unconventional aircraft configurations. Accurate aircraft engine noise prediction is an important component of overall aircraft system noise tools. In particular, the prediction of rotorstator interaction (RSI) noise, which is the tone or broadband noise produced as a result of the interaction between the fan wakes and fan exit guide vanes, continues to be of interest since it can be a dominant engine noise source. Understanding of the source mechanisms, in-duct propagation, and subsequent radiation to the far-field is necessary to develop and evaluate noise reduction concepts. Therefore, assessment of the cost/benefits of the available prediction tools, as well as development of improved methodologies, are essential.

Fan noise prediction tools incorporate methodologies ranging from empirical to fully computational. The empirical methods 11 are attractive, as they tend to require minimal computer resources and run times. However, empirical methods are limited in application in that they can not be confidently used for fan configurations (including acoustic treatment) that deviate significantly from those upon which the empirical method is based. Additionally, predictions are generally available only in the far-field and hence do not contain near-field information that may be required to perform additional analysis, such as acoustic scattering predictions. In contrast to empirical methods, computational methods rely on first principles and, in some instances, phenomenological considerations of the noise generation and propagation processes. Such methods have been developed for a number of fan noise sources $2 \sqrt{3}$ and specific configurations ${ }^{[-7]}$ The use of these methods requires more expertise than the empirical models and often requires access to fairly detailed aerodynamic and geometric input parameters from independent measurements and computations. As

\footnotetext{
${ }^{*}$ Research Scientist, Structural Acoustics Branch, Research Directorate, Member AIAA

${ }^{\dagger}$ Research Aerospace Engineer, M.S. 54-3, 21000 Brookpark Road, Cleveland, OH 44135, AIAA Associate Fellow.

${ }^{\ddagger}$ Senior Research Scientist, Aeroacoustics Branch, Research Directorate, Member AIAA
} 
such, these methods can require significantly more computer resources and run times compared to the empirical methods, but potentially offer a level of fidelity that allows more accurate assessment of current designs and development of noise reduction strategies. Recent assessment reports ${ }^{78}$ have addressed various aspects of these current fan noise prediction tools.

Following the paradigm of the previous assessments, a subsequent study $y^{9}$ investigated a well known empirical method, NASA's Aircraft Noise Prediction Program (ANOPP), 1 and a newly developed coupled computational approach via comparison with measured sideline acoustic measurements from a benchmark fan noise test. The specific fan configuration, the Advanced Ducted Propulsor (ADP) Fan 1, $10[11$ was chosen because it exhibited strong RSI

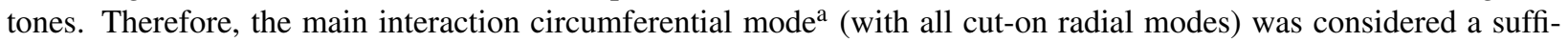
cient source description for the coupled computational approach. As anticipated, the computational approach provided detailed directivity information and afforded the ability to account for near-field effects. These capabilities were not available in the inherent far-field, one-third octave band empirical predictions. However, shortcomings in the source description of the computational approach were evident. Direct comparison with measured sideline data was problematic at off-peak directivity locations due to the presence of additional sources in the measured data. Results showed that further investigation into proper source specification for the computational approach was warranted.

The purpose of the current study is to use measured data to address previous acoustic source specification issues and determine if improved tonal RSI noise predictions can be obtained, ultimately providing improved understanding of the current acoustic propagation/radiation prediction tools. Specifically, the acoustic propagation and radiation portions of the coupled computational approach are used to predict rotor-stator interaction noise from another benchmark configuration, the NASA/GE Source Diagnostic Test (SDT) fan. Use of the SDT afforded access to fan noise source measurements, and therefore information beyond the main interaction circumferential mode, which were not available for the ADP. Based on these measurements, a number of source descriptions are used within the computational approach. Beginning with the dominant circumferential mode ${ }^{\mathrm{b}}$ (with all cut-on radial modes), additional circumferential modes (with all cut-on radial modes) are added to study their effect on the radiated sound field. As the relative phase of the source modes is an important parameter, a series of predictions in which the relative phases are randomized are also performed. The resulting acoustic predictions are compared with measurements to illustrate source effects and evaluate prediction quality. The test configuration and experimental measurement facilities are first presented in Section [I] A brief discussion of the computational approach, initially coupled with a fan noise source prediction code in the previous study, ${ }^{9}$ is then presented. Comparison of the predictions with sideline measurements are made in section IV Finally, concluding remarks regarding some of the more significant results are presented in Section $\square$

\section{Test Facility and Acoustic Measurements}

The selected fan test case for this study is taken from a previous assessment of fan noise prediction capabilities 8 involving a high bypass ratio fan stage called the NASA/GE Source Diagnostic Test (SDT) fan. The 22-inch diameter rotor was tested in the NASA Glenn 9-Foot by 15-Foot (9'x15') Low Speed Wind Tunnel (LSWT) (see fig. 11) in which sideline, as well as in-duct, acoustic measurements were acquired. The SDT fan, $\frac{13,14}{14}$ the cross-section of which is shown in figure 2. has a design corrected tip speed of $1,215 \mathrm{ft} / \mathrm{sec}$, a stage pressure ratio of 1.47, and bypass ratio of 8.9. The fan stage has 22 blades and 54 fan exit guide vanes. The fan speed conditions of interest, the details of which are provided in Table 1. are representative of the three certification points (approach, cutback, and takeoff), as well as two intermediate fan blade tip speeds. For this initial source investigation however, only the approach condition (61.7\% design speed) is used.

\section{A. Wind Tunnel Acoustic Measurements}

The 9'x15' wind tunnel, a schematic of which is shown in figure 3, is an open-loop, continuous-flow, anechoic wind tunnel facility. Acoustic measurements are acquired using a traversing microphone along the sideline placed 89.3 inches (approximately four fan diameters) from the fan axis. Data were taken at 48 positions in 2.5 -degree intervals starting at $25^{\circ}$ from the fan axis, with $0^{\circ}$ being the forward position upstream of the fan. Additionally, to obtain more angular coverage in the aft quadrant, three fixed microphone probes are placed in the rear of the test section. Together, the traversing probe and the fixed microphones result in 51 measurement locations that cover sideline emission angles (based on 0.1 Mach number) ranging from $25^{\circ}$ to $158^{\circ}$ relative to the mid-chord of the fan. All measured and predicted results in the study are referenced to these emission angles, herein also referred to as sideline angles.

\footnotetext{
${ }^{\mathrm{a}} m=-9$ at $2 \mathrm{xBPF}$ for the ADP

${ }^{\mathrm{b}}$ Based on blade/vane coun ${ }^{12}$ and evident in rotating rake data
} 


\section{B. Rotating Rake Acoustic Measurements}

In addition to sideline acoustic measurements, a rotating rake ${ }^{15 \mid 16}$ measurement system was used to provide a map of the acoustic duct modes present in the fan duct. Developed and implemented by NASA Glenn Research Center in the 1990s to measure turbofan duct acoustic modes, the system is a continuously rotating radial microphone rake that is inserted into the fan duct. For inlet measurements, 12 to 14 transducers are typically distributed in equal radial increments starting near the outer-wall to the duct centerline at the throat. For exhaust measurements, 6 to 8 transducers are typically distributed in equal radial increments starting near the outer-wall to the near inner wall at the duct exit plane. The rotating rake provides a complete map of the acoustic duct modes present in a ducted fan and has been used on a variety of test articles: from a low-speed, concept test rig, high-speed, scaled, wind tunnel models, to a full scale production turbofan engine.

The key concept behind the rotating rake technique is that by slowly rotating at a rate locked to the fan shaft speed (e.g., 1:200 speed ratio), a Doppler shift is imparted to the duct spinning modes that is based on the mode physics. The acoustic pressure profile may therefore be separated into circumferential modes. The radial modes are obtained by solving a least-squares-curve fit to these circumferential modes using the hard-wall cylindrical Bessel functions as the basis functions. The acoustic power level (PWL) for each mode is computed based on physical conditions directly from the mode pressure. For initial predictions in the investigation, the source modal amplitude and phase information were used to generate the source information for the computational approach. As information for all cut-on modes was available, the source description could be built up incrementally to study the effects of additional modes on the radiated noise.

\section{Prediction Code Description}

Although more detailed discussions of the codes have been presented previously, a brief description may be useful in understanding the prediction process. After introducing the individual components of the computational approach, details of the current implementation are discussed.

\section{A. CDUCT-LaRC}

In the computational approach, fan noise source information is passed to a duct propagation and radiation code. A suitable code, used in the previous study, for performing these predictions is the CDUCT-LaRC code. This code calculates the propagation of a given arbitrary acoustic potential source profile ahead of the fan face or aft of the exhaust guide vanes in the inlet or exhaust ducts, respectively. Subsequent to the propagation calculations, the code has the capability of computing the noise radiation field outside the duct. In addition to the ducts being acoustically lined in specified areas, other issues that make the propagation and radiation analysis complex include:

1. The duct may have a non-uniform circular or annular section. As a result, the flow in the duct may be nonuniform.

2. There may be a pylon and a bifurcation in the exhaust duct resulting in one or two C-shaped regions. This will completely change the character of acoustic wave propagation from that of an annular duct.

3. The acoustic lining on the duct wall may be nonuniform (i.e. circumferentially and axially segmented).

The CDUCT-LaRC code is composed of five distinct modules: 1) input and output specification, 2) Computational Fluid Dynamics (CFD) and acoustic grid generation, 3) background flow calculation, 4) duct acoustic propagation, and 5) duct acoustic radiation. All of the modules that currently make up the CDUCT-LaRC framework have been discussed previously 17 and are utilized in this study. However, this discussion will focus on the propagation and radiation modules, as they are most pertinent to this investigation.

The duct propagation module is based on the CDUCT code developed by Dougherty $\sqrt{18 \mid 19}$ and extended by Lan.20 This utilizes a parabolic approximation to the convected Helmholtz equation and offers a computationally efficient model that accounts for the complexities listed above. The CDUCT-LaRC code has been extended to allow a user to automatically perform multi-block propagation calculations. The grid connectivity is determined and data is transferred from upstream to downstream blocks without user intervention. Results of the propagation module include the acoustic potential or pressure within the duct, which may be utilized by the radiation module for acoustic radiation calculations.

The duct radiation model is based on the Ffowcs Williams-Hawkings (FW-H) equation with a penetrable data surface. ${ }^{21}$ Use of this equation for many acoustic problems has shown it to generally provide better results than 
the Kirchhoff formula for moving surfaces. Based on the background flow conditions and propagation solution, this module calculates the radiated acoustic pressure at various observer locations. The data surface may be taken to be the nacelle inlet or exhaust plane for inlet or aft-fan cases, respectively. However, provisions have also been made to account for the effects of the shear layer on the radiation.22 23. In this approach, the CDUCT-LaRC bypass duct propagation calculation is extended to a 'pseudo-duct' beyond the exhaust plane. The outer surface of the 'pseudoduct' is defined by the shear layer surface upon which a boundary condition similar to an acoustic liner boundary condition is applied. The development of the boundary condition is based on the satisfaction of two conditions: 1) the particle displacement must be continuous across the shear layer, and 2) the acoustic pressure must be continuous across the shear layer. Thus, an impedance boundary condition is obtained which is then applied on the outer surface of the 'pseudo-duct'.

\section{B. Implementation}

Before presenting predictions, further details on a few aspects of the computational implementation are beneficial. Figure 4 illustrates the computational grid topologies used in the inlet and exhaust predictions ${ }^{\mathrm{C}}$. The blocks used for inlet and aft interior duct propagation are shown in red and green wireframe, respectively. The 'pseudo-duct' is shown in blue wireframe at the furthest downstream extent. The source planes for the propagation calculations are located at the rotating rake measurement planes (approximately $2.5 \mathrm{in}$. upstream of the exhaust plane for exhaust predictions and $3.325 \mathrm{in}$. downstream from the inlet plane for inlet predictions). While CDUCT-LaRC can accept arbitrary source specification (i.e. it is not a modal code), it is often convenient to specify the acoustic source distribution in terms of duct modes. For situations in which the source pressure is available, this greatly simplifies the conversion to the required acoustic potential. Previously, 9 this information was obtained by using the LINFLUX ${ }^{824}$ code to compute the rotor-stator interaction tones generated as a result of the mean perturbations in the fan rotor wake impinging on the stator. In this study, the acoustic potential source profiles were computed using various combinations of the measured source modes obtained from the aforementioned rotating rake. Consistent with the mean flow considerations of the rotating rake modal decomposition, the Mach number at the source planes was taken to be uniform. Therefore, although non-uniform flows may be considered within CDUCT-LaRC, the mean flow for the current study was assumed to obey a one-dimensional Mach-Area relation.

An additional aspect of the prediction process that warrants further explanation is the implementation of the shear layer model. Following results from previous investigations, $22[23$ the impedance value to be applied on the shear layer surface obtained for the lowest order radial mode at the given circumferential mode, $m=-10$, was used for all modes. This meant that only a single impedance value was required and allowed all modes to be considered in a single calculation. To qualitatively illustrate the 'pseudo-duct' calculation, the contours of the real part of acoustic potential are shown in the interior block and 'pseudo-duct' for a sample prediction in fig. 5. The exposed (i.e. outer radial and axial) 'pseudo-duct' surfaces are then used as acoustic data surfaces for the subsequent FW-H acoustic radiation calculations. Based on previous studies, $\frac{9233}{a}$ a 'pseudo-duct' having an axial extent of approximately 5 times the annular duct radius $\left(r_{\max }-r_{\min }\right)$ was utilized in all subsequent predictions including the shear layer modeling. The propagation calculations were performed on inlet/aft internal computational domains having $(89,185,17)$ points and a 'pseudo-duct' domain having $(89,185,65)$ points in the radial, circumferential, and axial directions, respectively. This grid resolution was well above that required for most conditions considered. However, it was maintained so that one grid could be used for all computations while accommodating situations in which all cut-on source modes were included The efficiency of the CDUCT-LaRC code minimized the impact on computational resources, as a complete three-dimensional propagation and acoustic radiation calculation took approximately one minute on a single workstation $2.66 \mathrm{GHz}$ CPU.

\section{Results and Discussion}

Rotor-stator interaction noise predictions for the rotating rake/CDUCT-LaRC (RR/CDUCT-LaRC) approach at two times the blade passage frequency ( $2 \mathrm{xBPF}$ ) are compared with measured data at sideline locations consistent with the 9'x15' test. Here, rotating rake data was used directly for source input within the computational approach. The modal source power levels associated with the inlet and exhaust have been presented previously ${ }^{25}$ and their relative levels are illustrated in figure 6 . The increased power level and dominance of the main RSI circumferential mode $(m=-10)$ in the exhaust, as compared to the inlet, are evident. This will be further illustrated as predictions with

\footnotetext{
${ }^{c}$ Here, only one of the 22 fan blades and one of the 54 exit guide vanes are shown to simplify the figure

${ }^{\mathrm{d}}$ Circumferential mode numbers up to $\pm 26 / \pm 28$ and radial orders up to $10 / 4$ for inlet and aft cases, respectively.
} 
increasing modal source content are presented. These are followed by comparisons for additional computations in which the relative phase of the source modes were randomly selected over a number of trials.

It is important to note that the predictions were carried out for the single $2 \mathrm{xBPF}$ frequency, whereas the measured data was obtained in $5.9 \mathrm{~Hz}$ bands. The acoustic energy from the interaction tone will not be limited to a single frequency bin in the narrow band spectra. As a result, the energy in the four frequency bins surrounding 2xBPF (two on either side) was taken to belong to the interaction tone. The reported measured tone levels are therefore the sound pressure levels equal to $10 \log \left(\sum_{i=1}^{N} p^{2}\right)$ where $N=4$ (i.e. summation over the the four frequency bins). Using only one adjacent bin (i.e. $N=2$ ) on each side of $2 \mathrm{xBPF}$ lowered the levels by approximately $2 \mathrm{~dB}$.

In comparing measured and predicted levels, inlet and exhaust observers were considered separately. The inlet observer locations were taken to include sideline angles from approximately $25^{\circ}-90^{\circ}$. Exhaust observer locations were taken to include sideline angles from approximately $105^{\circ}-158^{\circ}$. Sideline angles from $90^{\circ}-105^{\circ}$ were excluded to avoid ambiguity in separating inlet/exhaust contributions in the measured data. An additional point concerning the three stationary aft microphones which are not part of the traverse system should also be made. Predictions and measurements were performed at the locations shown in figure 3 . However, for consistency, the levels reported at these three locations were extrapolated (on a lossless basis) to the 89.3 in. sideline distance consistent with the traverse location.

\section{A. Direct Rotating Rake Source}

Initial comparison between measured data and RR/CDUCT-LaRC rotor-stator interaction noise predictions at 2xBPF for the approach speed are presented in figures 7-9 The inlet results are shown in figure 7 for three different source descriptions based on rotating rake data: 1) the $m=-10$ circumferential mode with all cut-on radial modes, 2) the $m=-10$ and circumferential modes having total power levels within $10 \mathrm{~dB}$ (all cut-on radial modes), and 3) all cut-on (circumferential and radial) modes. Measurement and prediction locations are denoted with symbols and adjacent values are connected by solid lines to more clearly delineate trends. The lobed character is evident in the three predictions, although it is most apparent with the first source description. The addition of source modes having total power levels within $10 \mathrm{~dB}$ of the $m=-10$ circumferential mode lessens the lobed character and leads to increased acoustic levels at all angles. As mentioned earlier, this indicates that the radiated inlet sound field is not driven exclusively by the main interaction mode and there is significant acoustic power in these additional modes. Adding the rest of the cut-on modes leads to a slight modification of the directivity pattern with a corresponding change in level. The last two source descriptions lead to predicted directivity patterns that match the measure data quite well, with the exception of a drop in predicted levels near approximately $35^{\circ}$. Clearly, additional source content beyond the main interaction circumferential mode is needed to improve comparison with measured levels in the inlet for this configuration.

Turning to the exhaust predictions, results for which shear layer modeling was not included are shown in figure 8 The shear layer is known to have an effect on the radiated sound field and should be included when performing exhaust predictions. Nonetheless, these computations were performed to illustrate the directivity modifications brought about by the 'pseudo-duct' model and to provide additional data on source effects. The source descriptions used for the inlet predictions were again employed. However, as the power in the main interaction mode $(m=-10)$ was considerably higher than all other modes (see figure 6, the total power level criterion used for the second source iteration was increased to $15 \mathrm{~dB}$. Thus, the three different exhaust source descriptions based on measured rotating rake data were: 1) the $m=-10$ circumferential mode with all cut-on radial modes, 2) the $m=-10$ and circumferential modes having total power levels within $15 \mathrm{~dB}$ (all cut-on radial modes), and 3) all cut-on modes. Here, the change from the first to second source description does not modify the character of the directivity pattern as much as the inlet case. The location and level of peak directivity does not change and the general character is maintained. The relative phasing of the source modes in these two cases lead to significant destructive interference near the $145^{\circ}$ fixed microphone location. The inclusion of all cut-on modes does not appear to have a major impact, except at this location. Overall, there is moderate change in directivity at forward emission angles associated with the traverse, suggesting the dominance of the main interaction mode.

Continuing with the exhaust predictions, results with the inclusion of shear layer modeling are presented in figure 9 The same three measured rotating rake source descriptions used in the previous exhaust predictions were used: 1) the $m=-10$ circumferential mode with all cut-on radial modes, 2) the $m=-10$ and circumferential modes having total power levels within $15 \mathrm{~dB}$ (all cut-on radial modes), and 3) all cut-on modes. The effect of the shear layer model is clearly evident. In contrast to the previous exhaust predictions, the "null" observed at $145^{\circ}$ has been eliminated and more consistent predicted acoustic levels are obtained at the fixed microphone locations. The inclusion of additional source modes does not change the character of the directivity pattern as much as the inlet case, again suggesting that 
the main interaction circumferential mode predominantly defines the radiated pattern.

Comparison of the overall levels for inlet and aft predictions with measurements provides additional evidence to the greater importance of the main interaction circumferential mode $(m=-10)$ in the exhaust predictions relative to the inlet. The difference in SPL for larger inlet radiation angles and smaller exhaust angles (i.e. approaching $90^{\circ}$ from above and below), as well as the peak overall level, reveals the increased acoustic power in the exhaust at $2 x B P F$. This is also consistent with original SDT rotating rake measurements, ${ }^{25}$ for which the total acoustic power is over $12 \mathrm{~dB}$ higher in the exhaust than in the inlet.

\section{B. Random Phase Variation}

As mentioned previously, the rotating rake system has been extensively tested, providing valuable experimental acoustic databases for a number of configurations. In a previous assessment of fan noise prediction capabilities,$\frac{8}{8}$ typical uncertainty in measured tone power levels was estimated to be $\pm 3.4 \mathrm{~dB}$. However, estimation of the uncertainties in the relative phase relationships is much more problematic. Additionally, there may be situations in which modal power levels are in hand, but relative phase information is lacking. In light of this, a systematic study of the effects of randomized source modal phase on the resultant directivity pattern was investigated. The approach taken followed that described by Zlavog and Eversman ${ }^{26,27}$ in a series of statistical studies into the effects of randomized modal source power and/or phase on attenuation in lined ducts. In this study, the source modal amplitudes (and hence, power) were fixed to be those obtained from the rotating rake. The source modal phases, however, were allowed to randomly vary uniformly over the range $[0,2 \pi)$.

Initially, a few select cases were chosen for which predicted acoustic levels at each observer location were obtained over 1000 trials. From these, the mean, $\mu$, and standard deviation, $\sigma$, of the predicted SPL were computed to obtain some initial insight into the form of the probability distributions. Representative distributions of predicted radiated SPL for inlet and exhaust (without shear layer modeling) are shown in figures 10-12 For the inlet, locations of maximum SPL and maximum $\sigma$ were chosen over the range of inlet sideline angles. For the exhaust cases, similar criteria was used, except that the three fixed microphone locations were excluded from the selection process due to the behavior at $145^{\circ}$. Following Zlavog and Eversman, ${ }^{[27}$ the resulting range of radiated SPL was partitioned in bins of equal size ( 0.3 times the standard deviation) and the relative frequency (fractional number of occurrences) in each bin plotted versus the radiated SPL. Due to the bin size, this leads to a scaled (by the inverse of the bin width) version of the probability density function as compared to a traditional probability density function. This should be kept in mind, as a different standard deviation was calculated for each of the cases considered. While additional trials are in order before drawing final conclusions on the form of the distribution functions, it is interesting to note that these cases appear to follow trends similar to those seen in Zlavog and Eversman. ${ }^{27}$ The cases involving all cut-on modes have a slight positive skew, but appear to be trending toward a Gaussian distribution. The cases involving only the cut-on radial modes of the $m=-10$ circumferential mode appear to have more of a non-Gaussian character. As pointed out in the previous statistical study, some of the skewness may be due to the logarithmic mapping to SPL. With the completion of additional trials for all cases, functional fits to the probability distributions, including non-logarithmic mappings, will be investigated.

In parallel to the study of the probability distributions for select cases, RR/CDUCT-LaRC predicted acoustic levels at each observer location for all of the inlet and exhaust cases considered previously in Subsection A were obtained over 100 trials. In figures 13 15, the predicted mean SPL (i.e. mean directivity pattern) is plotted for comparison with the single instance results from Subsection A as well as measured data. The single instance (i.e. initial predictions using full rotating rake data) results are represented by dashed lines, while the measured data is represented by solid lines. Also included in these figures are error bars denoting a range of $\pm \sigma$ above/below the mean values. In all cases, randomization of the relative phases tends to smooth out smaller variations in the directivity pattern, although larger peaks are maintained. However, it can also be seen that the dips in predicted inlet levels around $35^{\circ}$ and aft (without shear layer) levels around $145^{\circ}$ are removed. As more modes are included in the source description, the standard deviations also tends to become more consistent over the extent of the observer arc.

In the inlet (figure 13), the shape of the directivity pattern is generally well captured by predictions. However, the mean level falls below both single instance and measured values. This may be a result of the multi-modal nature of the acoustic source. Again, inclusion of all cut-on modes improves the prediction. In this case, mean and measured values generally differ by one standard deviation. At some sideline angles the difference is greater, but well within $2 \sigma$ (or within the $95 \%$ confidence interval if the distribution is Gaussian). As in the single instance case, it is clear that additional source information is needed beyond the $m=-10$ circumferential mode to obtain acceptable comparison with measured data.

As mentioned earlier, randomization appears to have alleviated the extreme behavior in the aft (without shear layer) 
predictions. In contrast to the inlet case, figure 14 shows that the mean levels remain on the order of the measured values. As seen in figure 15, inclusion of the shear layer model greatly improves the comparison with measured data at the aft sideline angles. The levels at the three fixed microphone locations are much closer to measured values. Once again, mean levels for the aft predictions generally remain within one standard deviation of the measured values, certainly closer than in the randomized inlet cases. In further contrast to the inlet case, the inclusion of additional source modes leads to smaller localized changes in directivity. The dominance of the $m=-10$ circumferential mode would appear to be a controlling factor in the behavior.

Overall, comparisons between predicted and measured directivity patterns are quite good. The inclusion of additional modal source information greatly improved inlet predictions, with less effect on the aft predictions. The randomization of source mode relative phases tended to smooth out the directivity patterns and generally improved the shape relative to the measured data.

The randomization procedure employed represents the extreme range of phase variation, whereas some modes may in fact have a stationary relative phase relationships. For example, all radial modes for a given circumferential mode might be phase locked. Initial investigations of this situation for the inlet have shown minimal change over full randomization when all cut-on modes are considered. However, further investigation is warranted.

\section{Concluding Remarks}

Previous investigations have shown that the details of the acoustic source are extremely important in predicting acoustic propagation within and radiation from hardwall and treated duct configurations $\frac{8 \mid 926}{20}$ The current study addressed source specification issues for the case of rotor-stator interaction to illustrate changes in 2xBPF predictions when additional source content was included. Following previous statistical studies, ${ }^{[27}$ the influence of relative phase between source modes was also shown through numerical experimentation. Examination of the results from these analyses on the SDT configuration suggest the following:

- For the inlet predictions, the radiated sound field was not driven exclusively by the main interaction mode $(m=-10)$ and there was significant acoustic power in the additional source modes. In situations such as this, predictions require additional source content beyond the main interaction circumferential mode to improve comparison with measured levels.

- For the exhaust predictions, the effect of the shear layer model was clearly evident. Inclusion of additional source modes did not change the character of the directivity pattern as much as the inlet case. The main interaction circumferential mode controlled the radiated pattern. In such a situation, comparison between predicted and measured levels do not significantly improve when additional source content is included.

- Given source modal power levels, randomization of the relative phases improved the shape of the predicted directivity patterns relative to measurements. Furthermore, predicted levels were generally within $\pm \sigma$ (and well within $\pm 2 \sigma$ ) of measured values.

- Random phase probability distributions obtained from current trials indicated that the SPL distribution at individual observer locations may be non-Gaussian when the single source circumferential mode was considered. However, when all cut-on source modes were included, the distribution tended more toward Gaussian. This is in line with conclusions drawn in a previous statistical study ${ }^{27}$ related to source effects on attenuation in lined ducts. Further investigation with a larger number of trials and additional cases is warranted.

\section{Acknowledgments}

The authors wish to thank Dr. Dan Sutliff for his assistance with the rotating rake data. This research was funded by the Subsonic Fixed Wing Project of NASA's Fundamental Aeronautics Program.

\section{References}

${ }^{1}$ Zorumski, W. E., “Aircraft Noise Prediction Program Theoretical Manual,” NASA TM 83199, National Aeronautics and Space Administration, 1982.

${ }^{2}$ Meyer, H. D. and Envia, E., "Aeroacoustic Analysis of Turbofan Noise Generation,” NASA CR 4715, 1996.

${ }^{3}$ Nallasamy, N. and Envia, E., "Computation of Rotor Wake Turbulence Noise," Journal of Sound and Vibration, Vol. 282, No. 3, 2005.

${ }^{4}$ Free Field Technologies, Louvain-la-Neuve, Belgium, MSC.ACTRAN 2005 User's Manual, 2005. 
${ }^{5}$ Eversman, W., "Mapped Infinite Wave Envelope Elements for Acoustic Radiation in a Uniformly Moving Medium," Journal of Sound and Vibration, Vol. 224, 1999, pp. 665-687.

${ }^{6}$ Lan, J. H. and Breard, C., "Development and Validation of a 3D Linearized Euler Solver," AIAA Paper 2006-2585, 2006.

${ }^{7}$ Watson, W. R., Nark, D. M., and Jones, M. G., "Assessment of 3-D Codes for Predicting Liner Attenuation in Flow Ducts," AIAA Paper 2008-2828, 2008.

${ }^{8}$ Envia, E., Tweed, D. L., Wooward, R. P., Elliott, D. M., Fite, E. B., Hughes, C. E., Podboy, G. G., and Sutliff, D. L., "An Assessment of Current Fan Noise Prediction Capability," AIAA Paper 2008-2991, 2008.

${ }^{9}$ Nark, D. M., Envia, E., and Burley, C. L., "Fan Noise Prediction with Applications to Aircraft System Noise Assessment," AIAA Paper 2009-3291, 2009.

${ }^{10}$ Dittmar, J. H., Elliott, D. M., and Bock, L. A., "Some Acoustic Results from the Pratt and Whitney Advanced Ducted Propulsor - Fan 1," NASA TM 1999-209049, 1999.

${ }^{11}$ Jeracki, R. J., "Comprehensive Report of Fan Performance from Duct Rake Instrumentation on 1.294 Pressure Ratio, $8.06 \mathrm{ft} / \mathrm{sec}$ Tip Speed Turbofan Simulator Models," NASA TM 2006-213863, 2006.

${ }^{12}$ Tyler, J. M. and Sofrin, T. G., “Axial Flow Compressor Noise Studies,” SAE Transactions, Vol. 70, 1962, pp. 309-332.

${ }^{13}$ Hughes, C. E., "Aerodynamic Performance of Scale-Model Turbofan Outlet Guide Vanes Designed for Low Noise," AIAA Paper 2002-0374, 2002.

${ }^{14}$ Woodward, R. P., Hughes, C. E., Jeracki, R. J., and Miller, C. J., "Fan Noise Source Diagnostic Test - Far Field Acoustic Results," AIAA Paper 2002-2427, 2002.

${ }^{15}$ Sutliff, D. L., "Rotating Rake Turbofan Duct Mode Measurement System,” NASA CR 213828, 2005.

${ }^{16}$ Sutliff, D. L., "Turbofan Duct Mode Measurements Using a Continuously Rotating Microphone Rake," International Journal of Aeroacoustics, Vol. 6, No. 2, 2007, pp. 147-170.

${ }^{17}$ Nark, D. M., Farassat, F., Pope, D. S., and Vatsa, V., "The Development of the Ducted Fan Noise Propagation and Radiation Code CDUCTLaRC," AIAA Paper 2003-3242, 2003.

${ }^{18}$ Dougherty, R. P., “A Wave-Splitting Technique for Nacelle Acoustic Propagation,” AIAA Paper 97-1652, 1997.

${ }^{19}$ Dougherty, R. P., "A Parabolic Approximation for Flow Effects on Sound Propagation in Nonuniform, Softwall, Ducts," AIAA Paper 99$1822,1999$.

${ }^{20}$ Lan, J. H., “Turbofan Duct Propagation Model,” NASA CR 2001-211245, 2001.

${ }^{21}$ Brentner, K. B. and Farassat, F., "Analytical Comparison of the Acoustic Analogy and Kirchhoff Formulation for Moving Surfaces," AIAA Journal, Vol. 36, No. 8, 1998, pp. 1379-1386.

${ }^{22}$ Nark, D. M., Farassat, F., Pope, D. S., and Vatsa, V., “A Model for Shear Layer Effects on Engine Noise Radiation,” AIAA Paper 2004-2992, 2004.

${ }^{23}$ Nark, D. M. and Farassat, F., “CDUCT-LaRC Status - Shear Layer Refraction and Noise Radiation,” AIAA Paper 2006-2587, 2006.

${ }^{24}$ Verdon, J. M., "Linearized Unsteady Aerodynamic Analysis of the Acoustic Response to Wake/Blade-Row Interaction,” NASA CR 2001210713, 2001.

${ }^{25}$ Heidelberg, L. J., "Fan Noise Source Diagnostic Test - Tone Modal Structure Results," AIAA Paper 2002-2428, 2002.

${ }^{26}$ Zlavog, G. and Eversman, W., "Source effects on attenuation in lined ducts. Part I: A statistically based computational approach," Journal of Sound and Vibration, Vol. 307, No. 1-2, 2007, pp. 113-138.

${ }^{27}$ Zlavog, G. and Eversman, W., "Source effects on attenuation in lined ducts. Part II: Statistical properties," Journal of Sound and Vibration, Vol. 307, No. 1-2, 2007, pp. 139-151.

\begin{tabular}{|c|c|c|}
\hline Condition & Corrected RPM & \% Design Speed \\
\hline \hline Approach & 7,809 & $61.7 \%$ \\
\hline- & 9,493 & $75.0 \%$ \\
\hline Cutback & 11,075 & $87.5 \%$ \\
\hline- & 11,771 & $93.0 \%$ \\
\hline Takeoff & 12,657 & $100.0 \%$ \\
\hline
\end{tabular}

Table 1: SDT Model Fan Tip Speed Conditions 


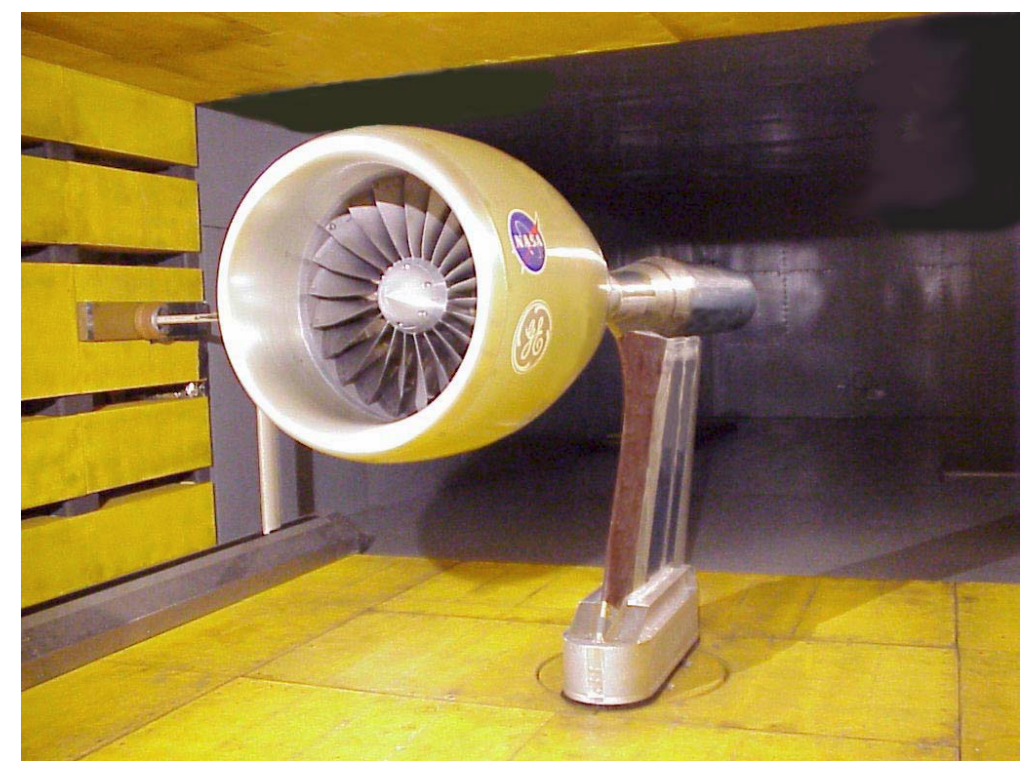

Figure 1: Source Diagnostic Test (SDT) model fan installed in the 9'x15' Low Speed Wind Tunnel.

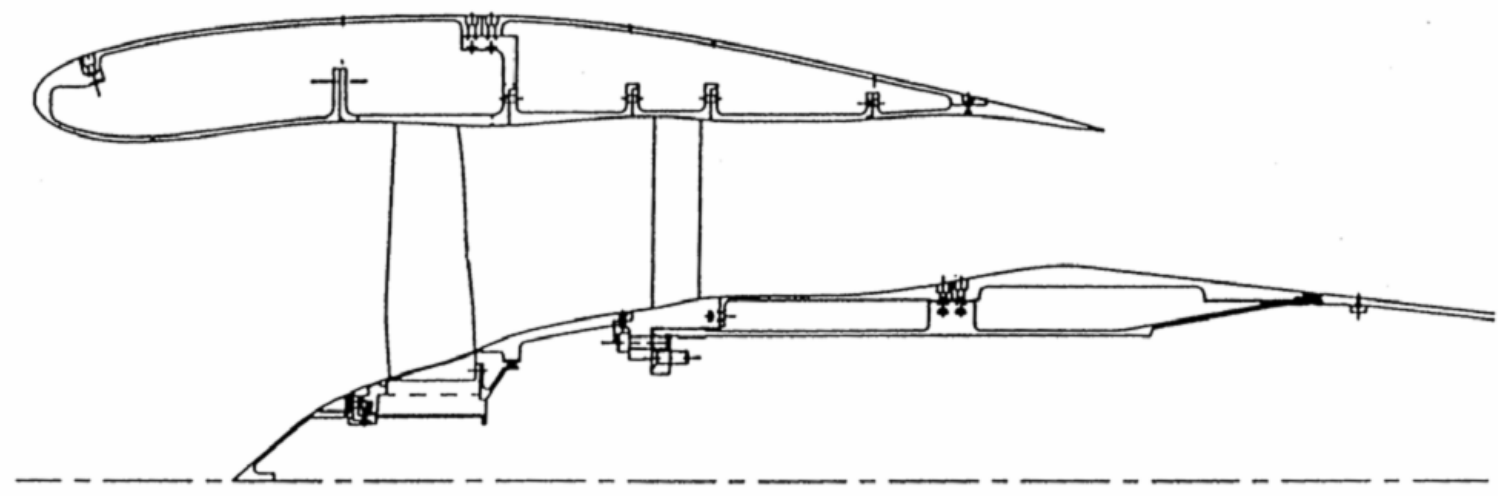

Figure 2: SDT model fan stage. 


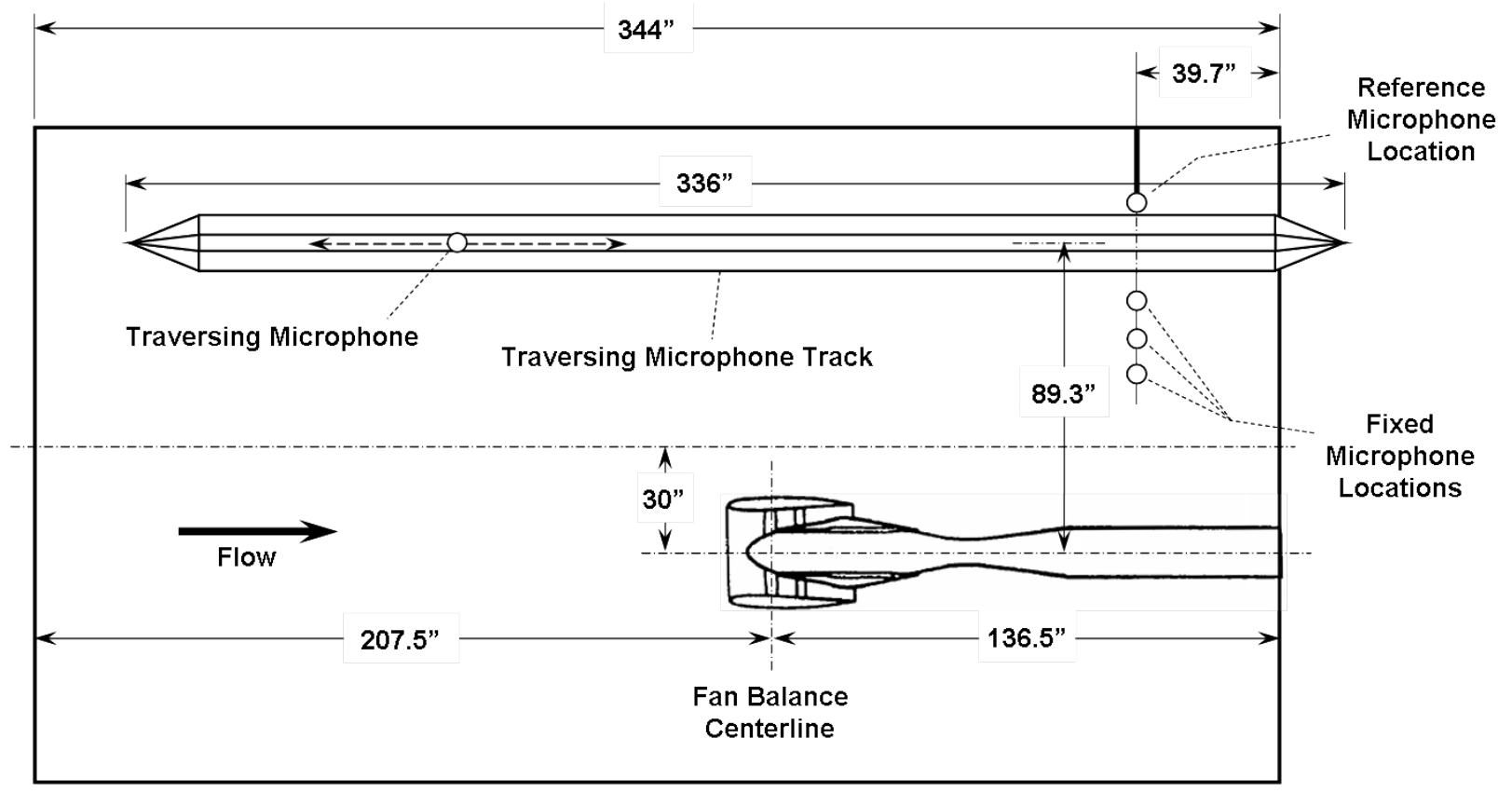

Figure 3: Top view of the 9' $\times 15$ ' test section illustrating model fan installation, as well as traversing microphone and three fixed aft microphones. All dimensions are in inches.

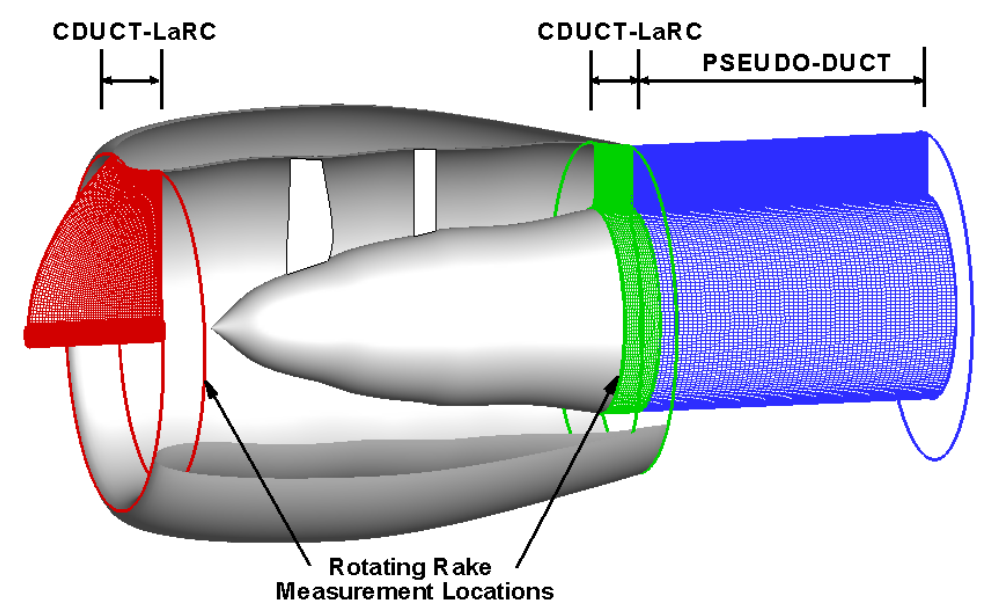

Figure 4: Block topology used for RR/CDUCT-LaRC predictions. The CDUCT-LaRC internal inlet and aft duct propagation blocks are shown in red and green, respectively. The 'pseudo-duct' block is represented in blue wireframe. The Rotating Rake location (and hence source plane) is at the furthest internal extent of both the inlet and aft CDUCTLaRC blocks. Note that only one of the fan blades and one of the exit guide vanes are shown to simplify the figure. 


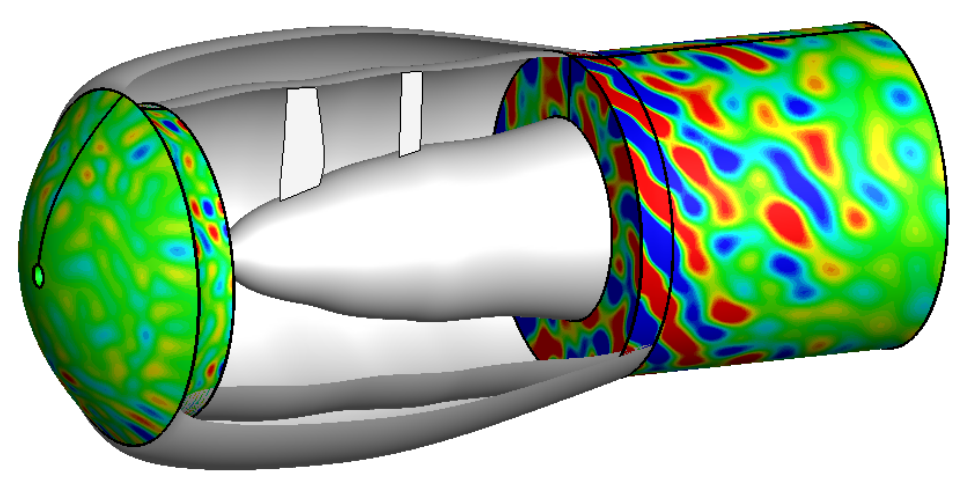

Figure 5: Qualitative inlet and aft acoustic propagation predictions with 'pseudo-duct' showing contours of the real part example of acoustic potential. The exposed surfaces of the inlet grid and 'pseudo-duct' are used as the source surface in subsequent $\mathrm{FW}-\mathrm{H}$ acoustic radiation predictions.

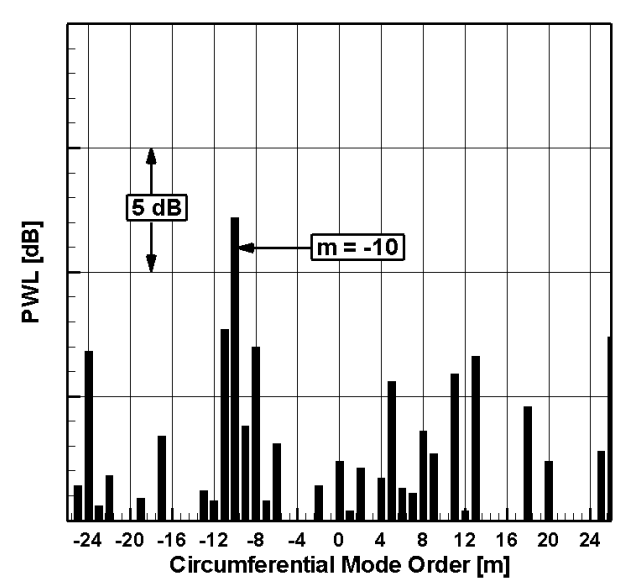

(a) Inlet

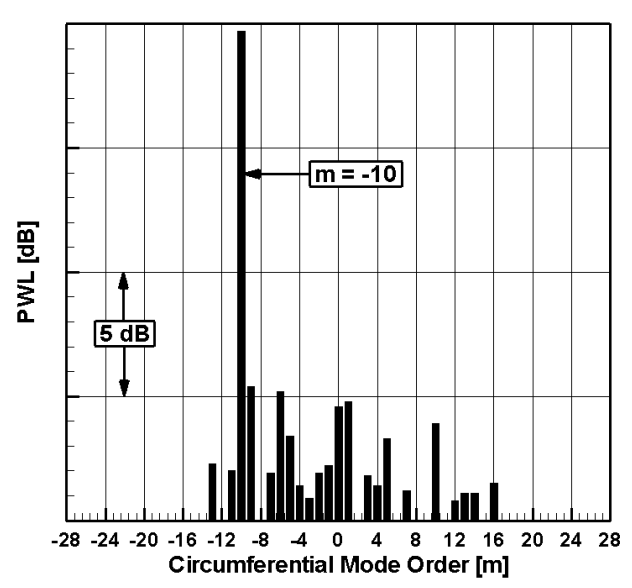

(b) Exhaust

Figure 6: Inlet and exhaust 2xBPF modal power distributions at approach speed. (See Heidelberg 25 ). 


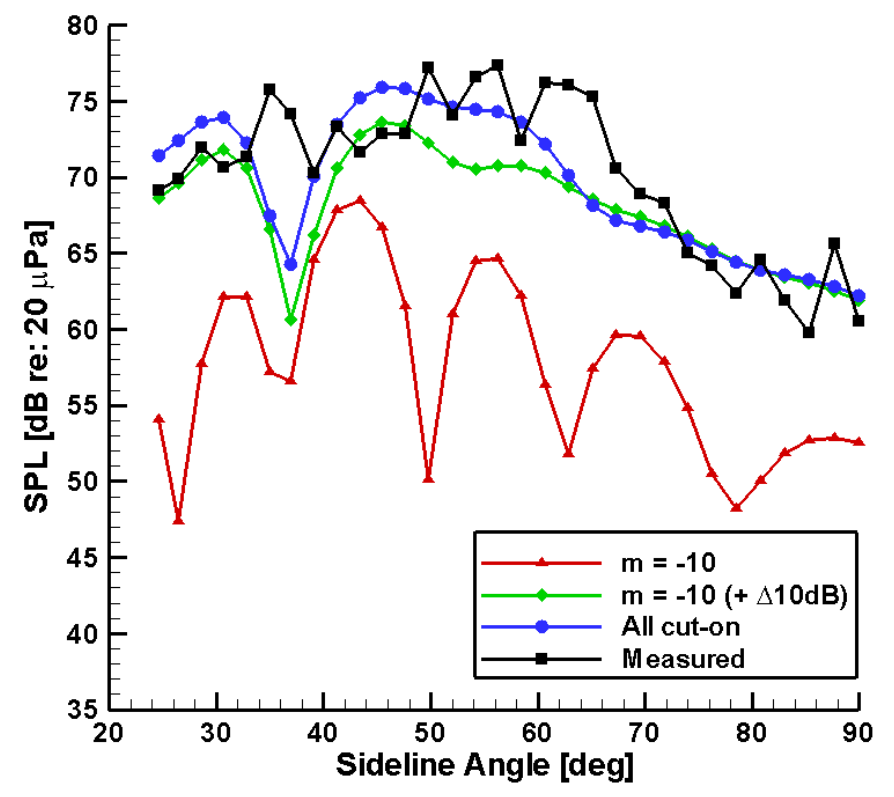

Figure 7: 2xBPF inlet RR/CDUCT-LaRC predictions and 9'x15' measured data at approach speed.

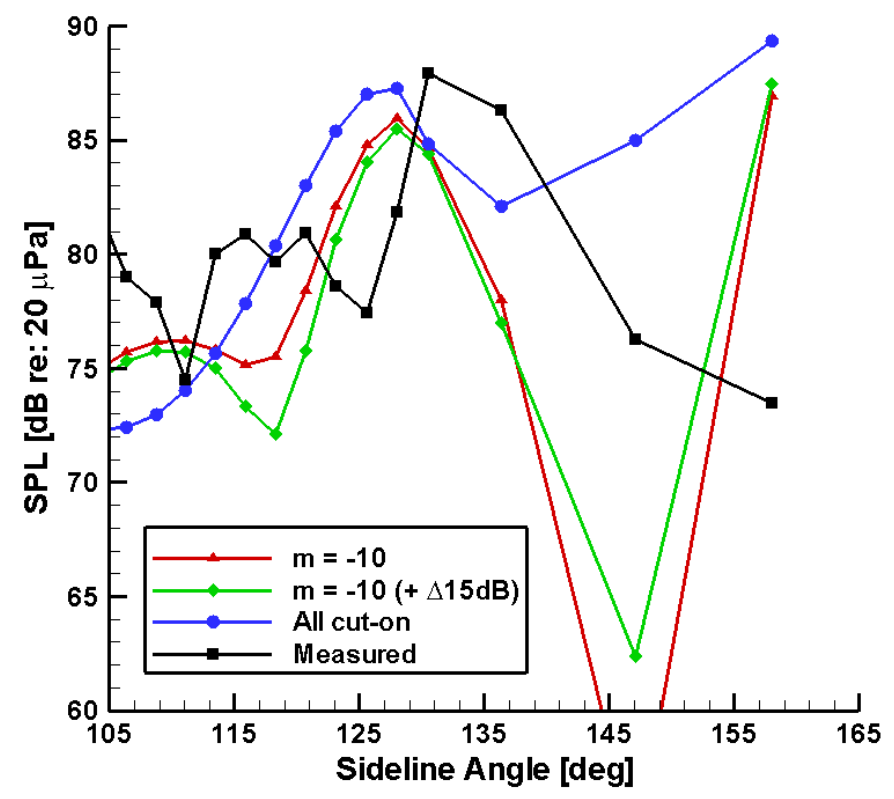

Figure 8: 2xBPF exhaust RR/CDUCT-LaRC predictions and 9'x15' measured data at approach speed. Note that the predictions do not include the shear layer effects. 


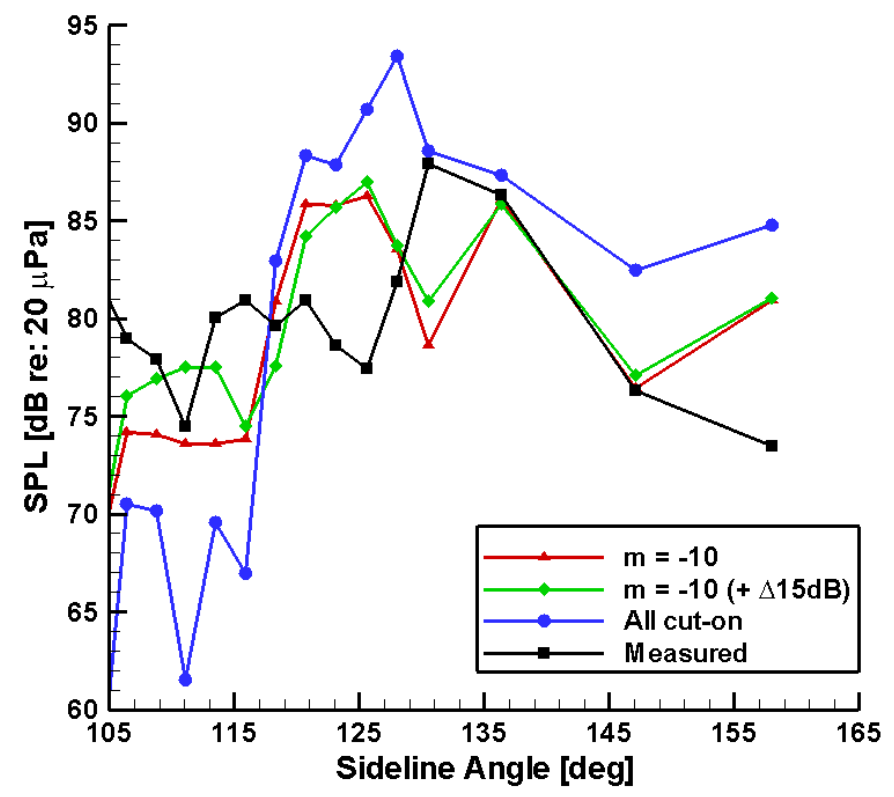

Figure 9: 2xBPF exhaust RR/CDUCT-LaRC predictions and 9'x15' measured data at approach speed. Note that the predictions include the 'pseudo-duct' to model shear layer effects.

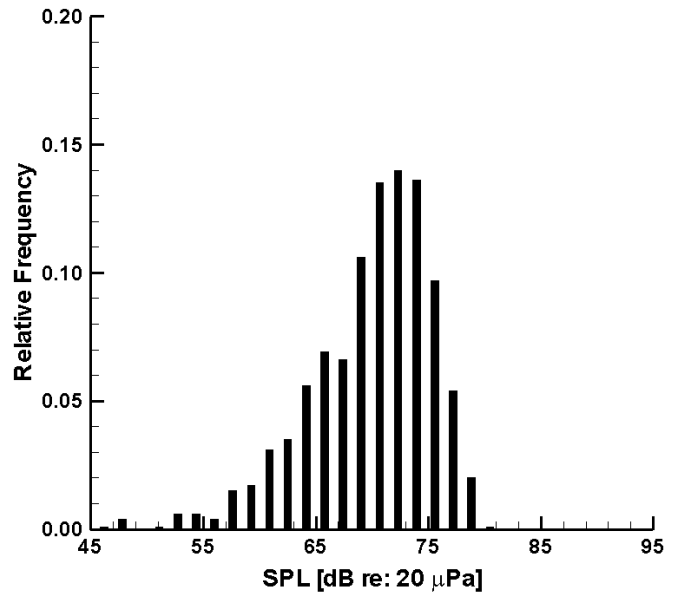

(a) Maximum SPL $\left(\theta=\sim 43^{\circ}\right.$; See figure $13 \mathrm{c}$

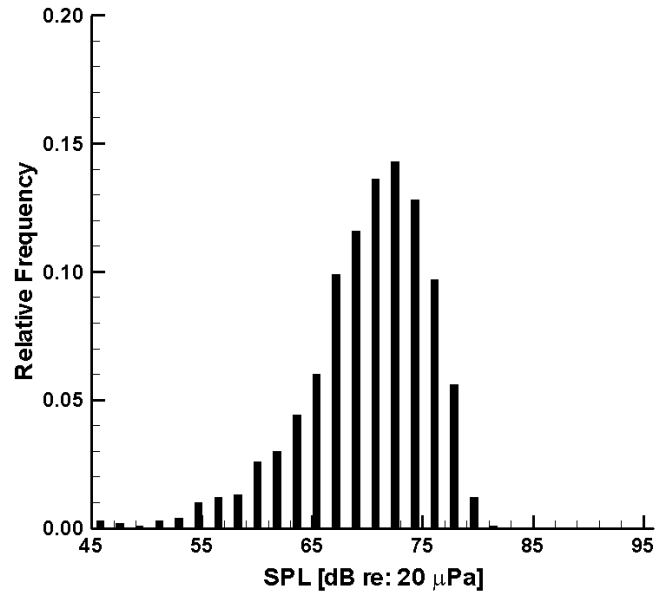

(b) Maximum $\sigma\left(\theta=\sim 48^{\circ}\right.$; See figure $13 \mathrm{c}$

Figure 10: 2xBPF RR/CDUCT-LaRC predicted inlet radiated SPL distribution for 1000 trials at approach speed including all cut-on modes. 


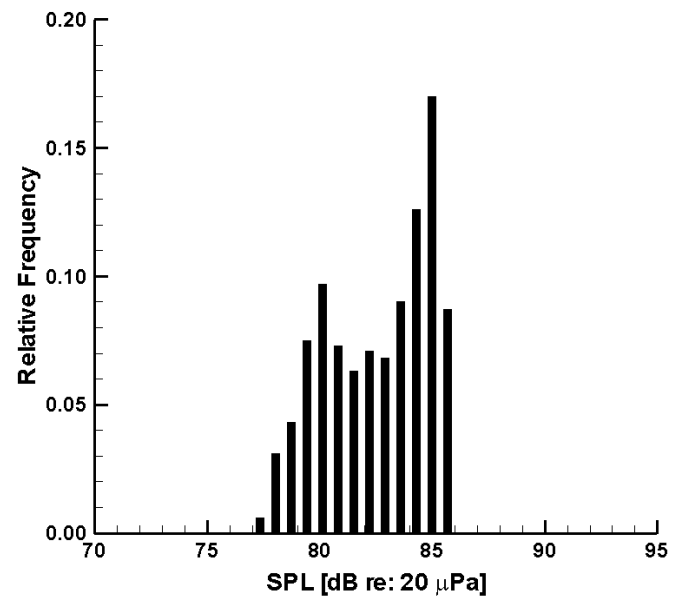

(a) Maximum SPL $\left(\theta=\sim 130^{\circ}\right.$; See figure 14a

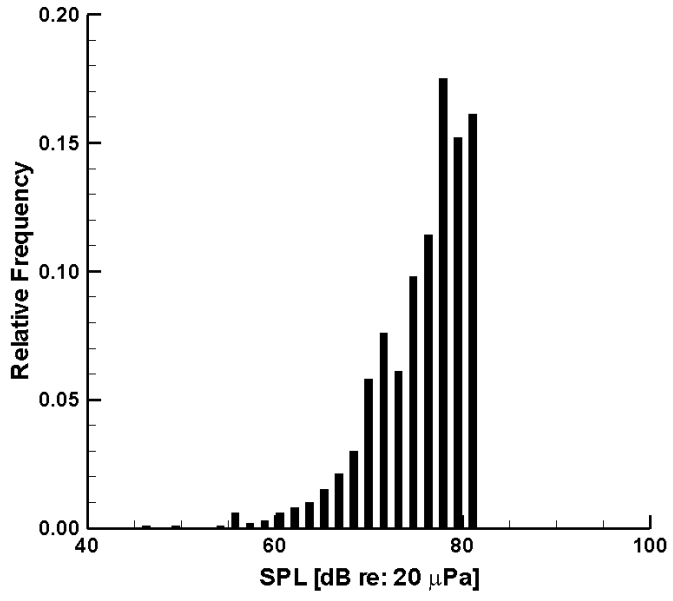

(b) Maximum $\sigma\left(\theta=\sim 109^{\circ}\right.$; See figure 14a

Figure 11: 2xBPF RR/CDUCT-LaRC predicted exhaust radiated SPL distribution for 1000 trials at approach speed including only the $m=-10$ circumferential mode (all cut-on radial modes). Note that the predictions do not include modeling for shear layer effects.

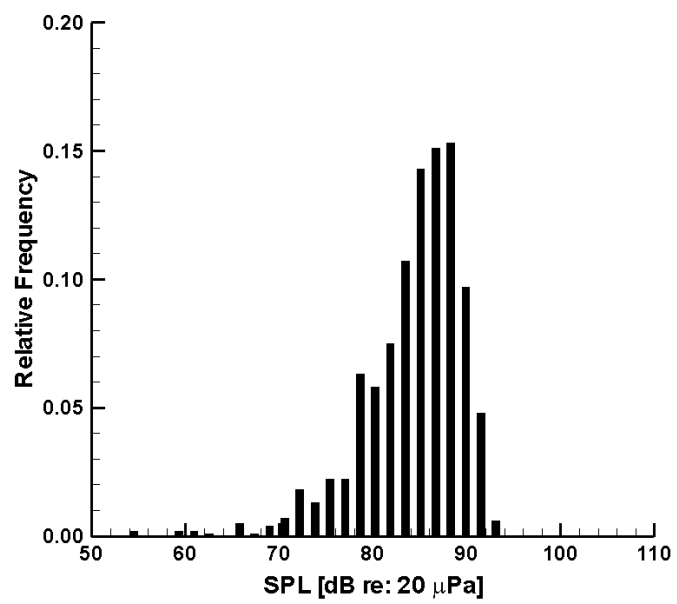

(a) Maximum SPL $\left(\theta=\sim 130^{\circ}\right.$; See figure $14 \mathrm{c}$

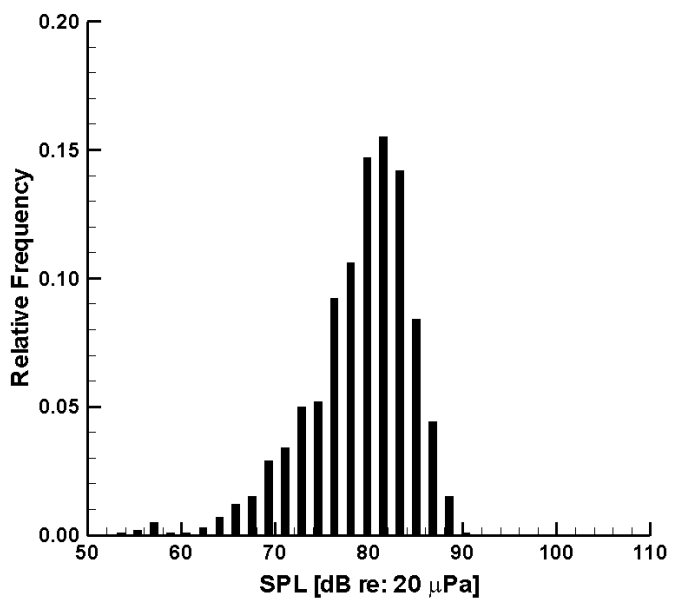

(b) Maximum $\sigma\left(\theta=109^{\circ}\right.$; See figure $14 \mathrm{c}$

Figure 12: 2xBPF RR/CDUCT-LaRC predicted exhaust radiated SPL distribution for 1000 trials at approach speed including all cut-on modes. Note that the predictions do not include modeling for shear layer effects. 

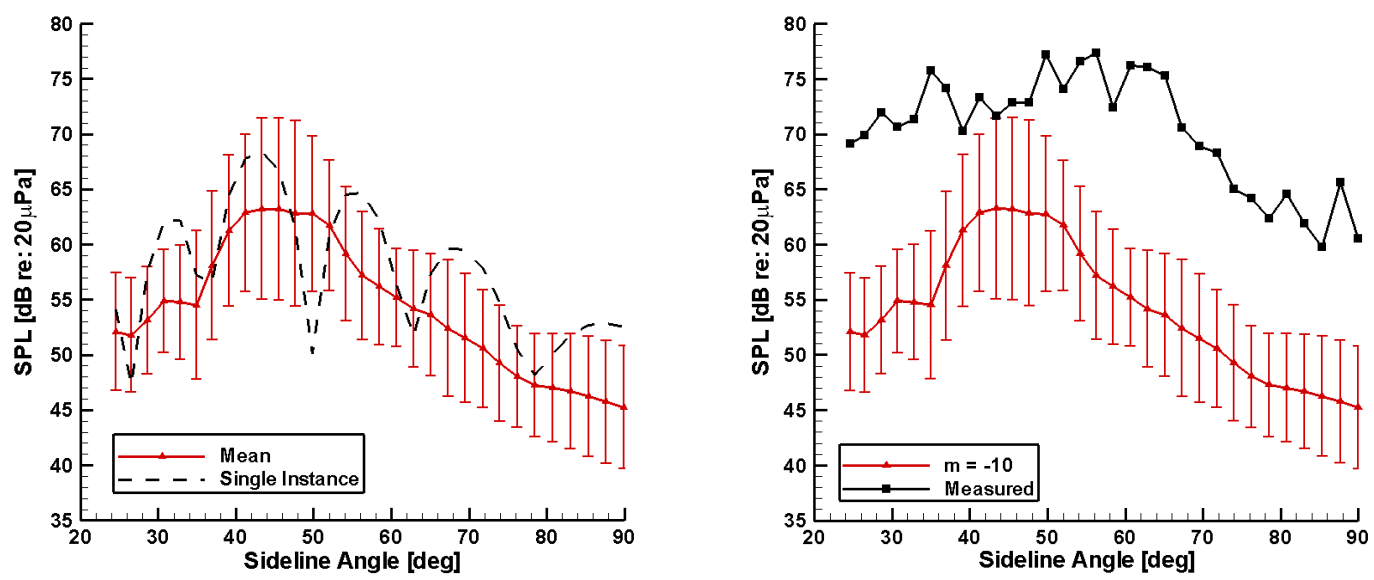

(a) $m=-10$ circumferential mode (all cut-on radial modes)
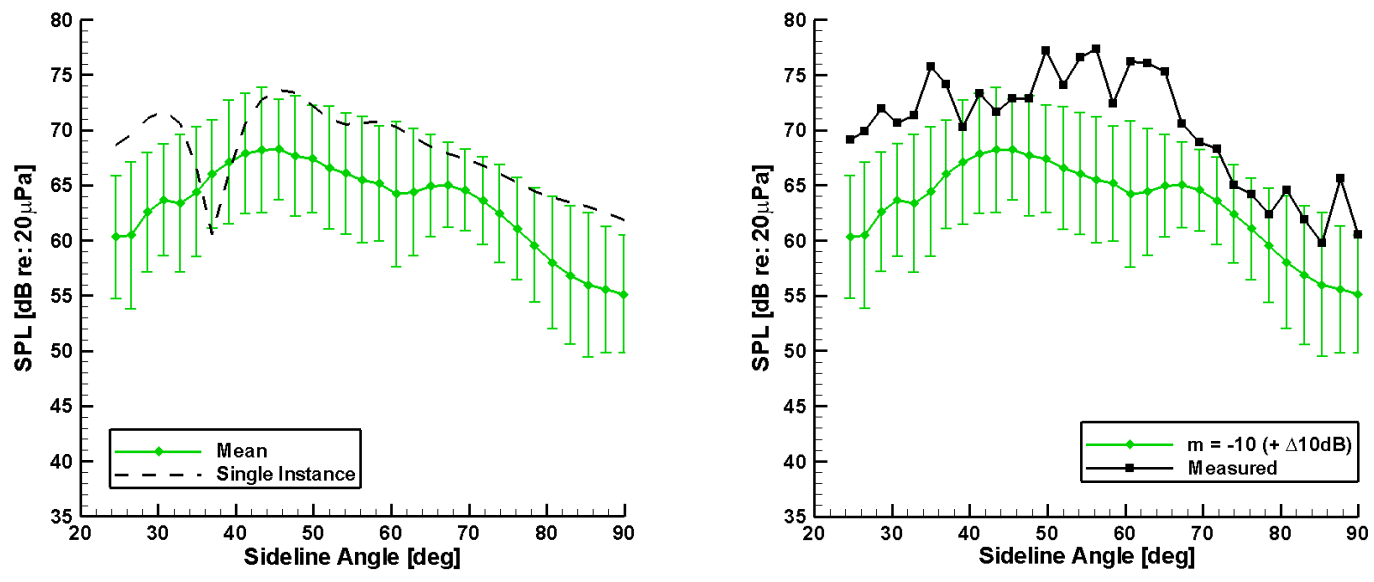

(b) $m=-10$ and circumferential modes having total power levels within $10 \mathrm{~dB}$ (all cut-on radial modes)
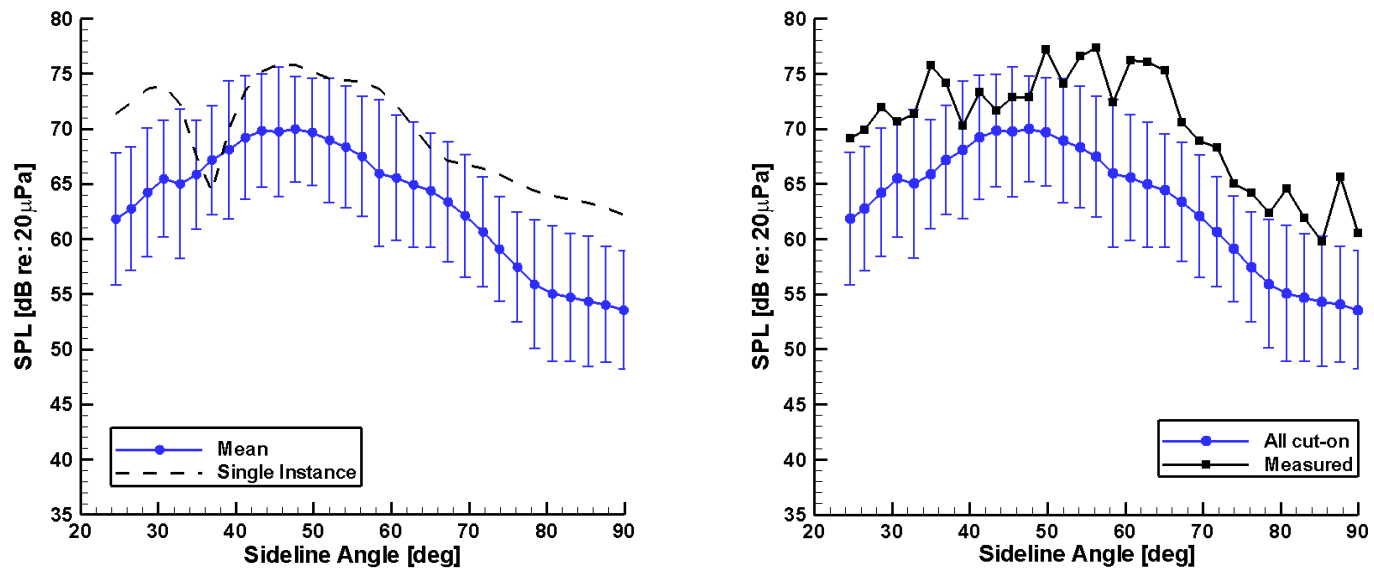

(c) All cut-on modes

Figure 13: 2xBPF inlet RR/CDUCT-LaRC (randomized phase) and 9'x15' measured data at approach speed. Dashed lines represent the single instances using complete rotating rake data for source specification. Solid lines with square symbols represent 9'x15' measured data. Error bars on predicted quantities denote a range of $\pm \sigma$. 

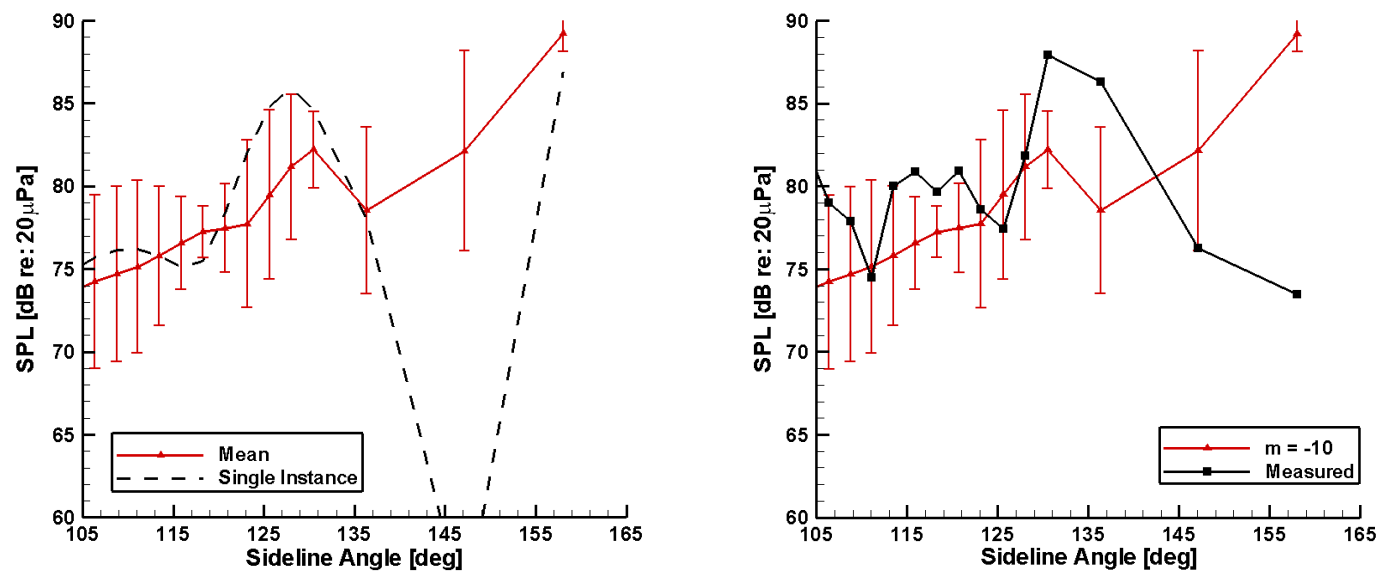

(a) $m=-10$ circumferential mode (all cut-on radial modes)
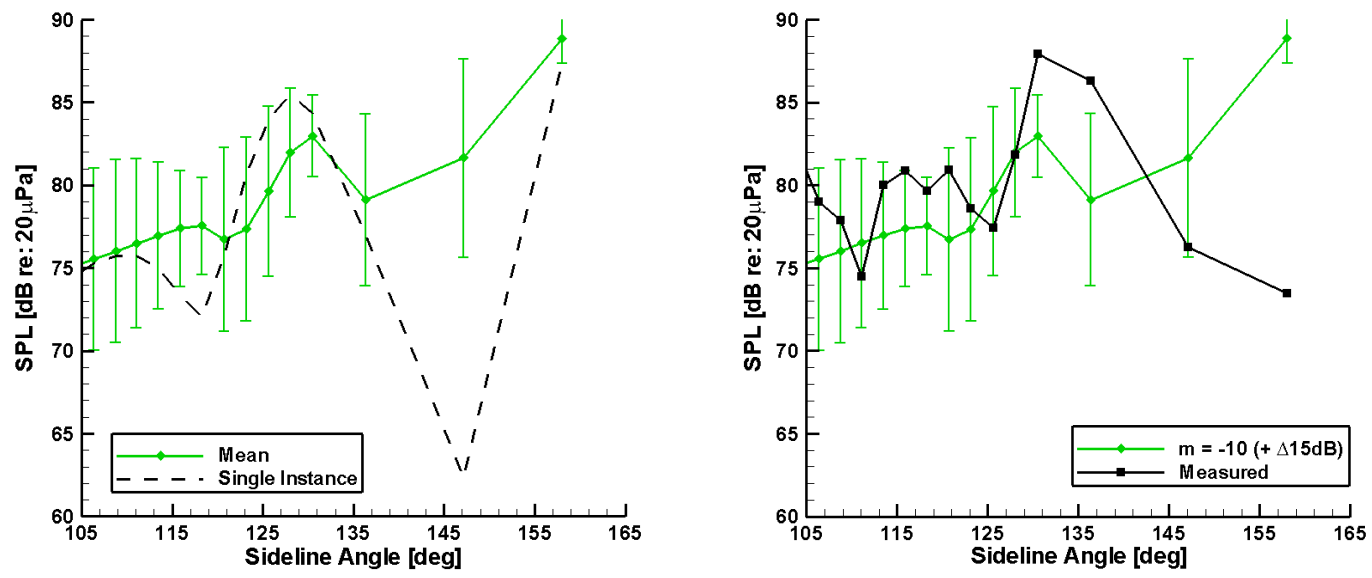

(b) $m=-10$ and circumferential modes having total power levels within $15 \mathrm{~dB}$ (all cut-on radial modes)
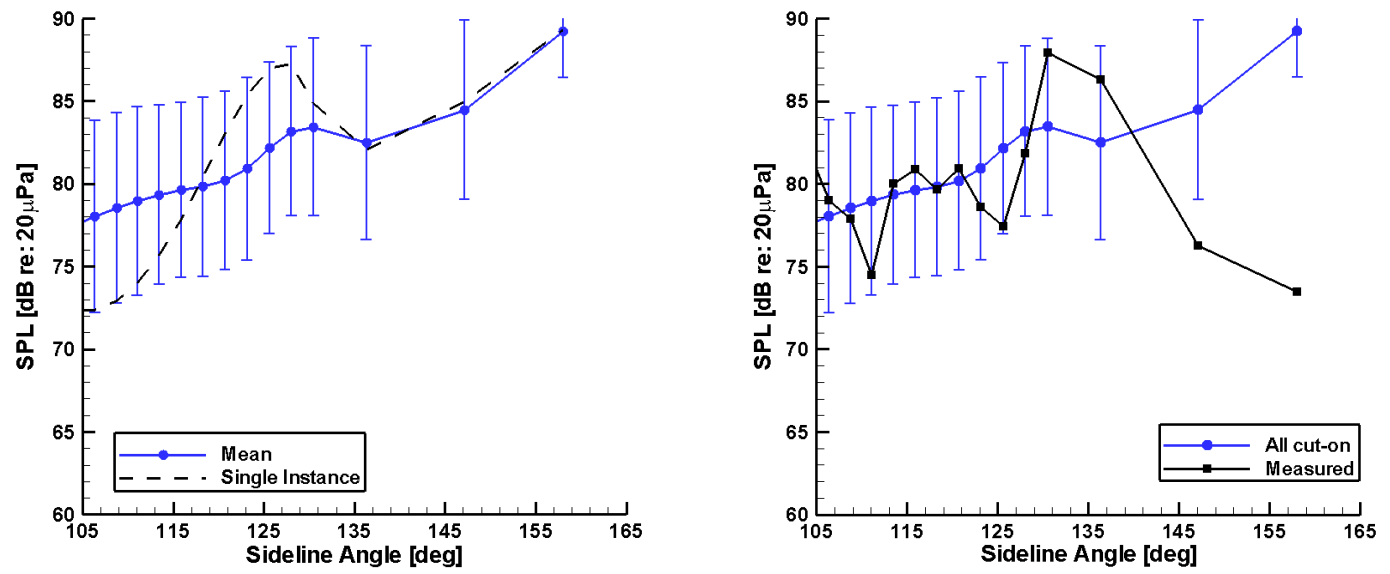

(c) All cut-on modes

Figure 14: 2xBPF exhaust RR/CDUCT-LaRC (randomized phase) predictions and 9'x15' measured data at approach speed. Dashed lines represent the single instances using complete rotating rake data for source specification. Solid lines with square symbols represent 9'x15' measured data. Error bars on predicted quantities denote a range of $\pm \sigma$. Note that the predictions do not account for shear layer effects. 

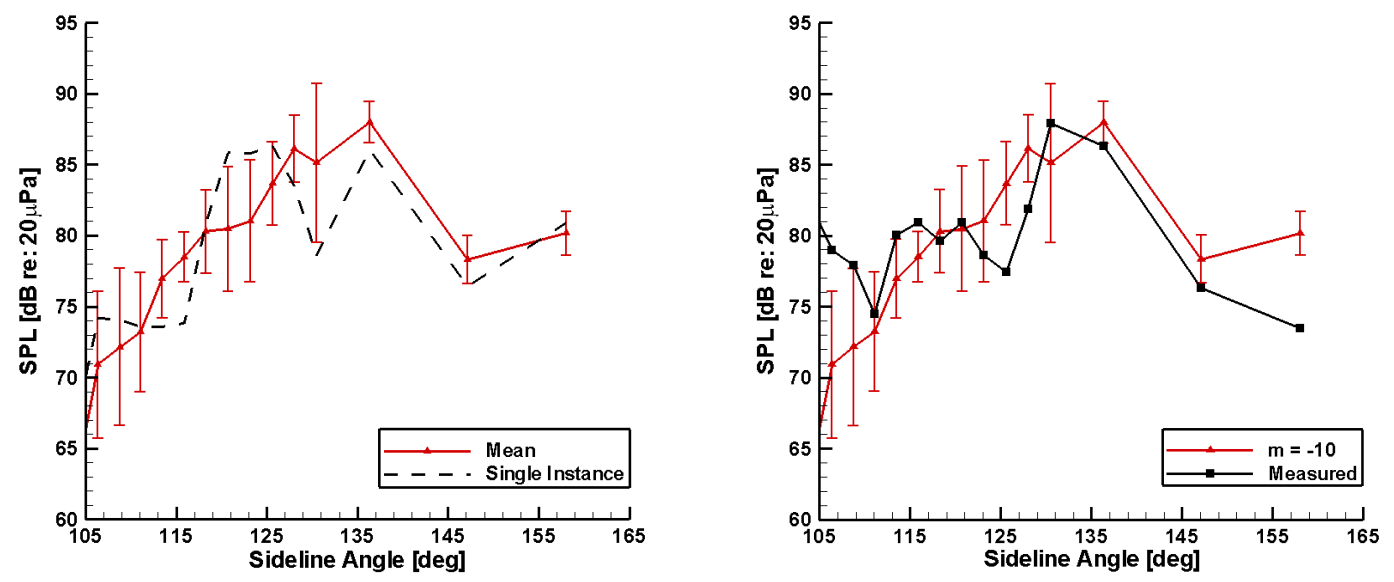

(a) $m=-10$ circumferential mode (all cut-on radial modes)
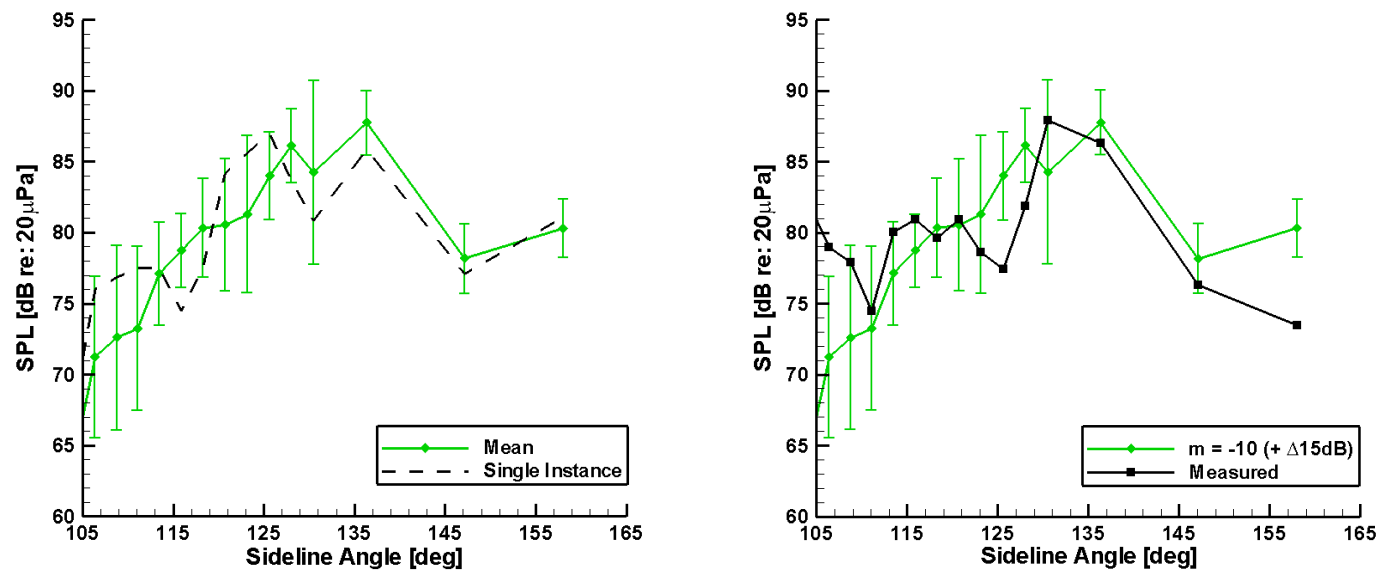

(b) $m=-10$ and circumferential modes having total power levels within $15 \mathrm{~dB}$ (all cut-on radial modes)
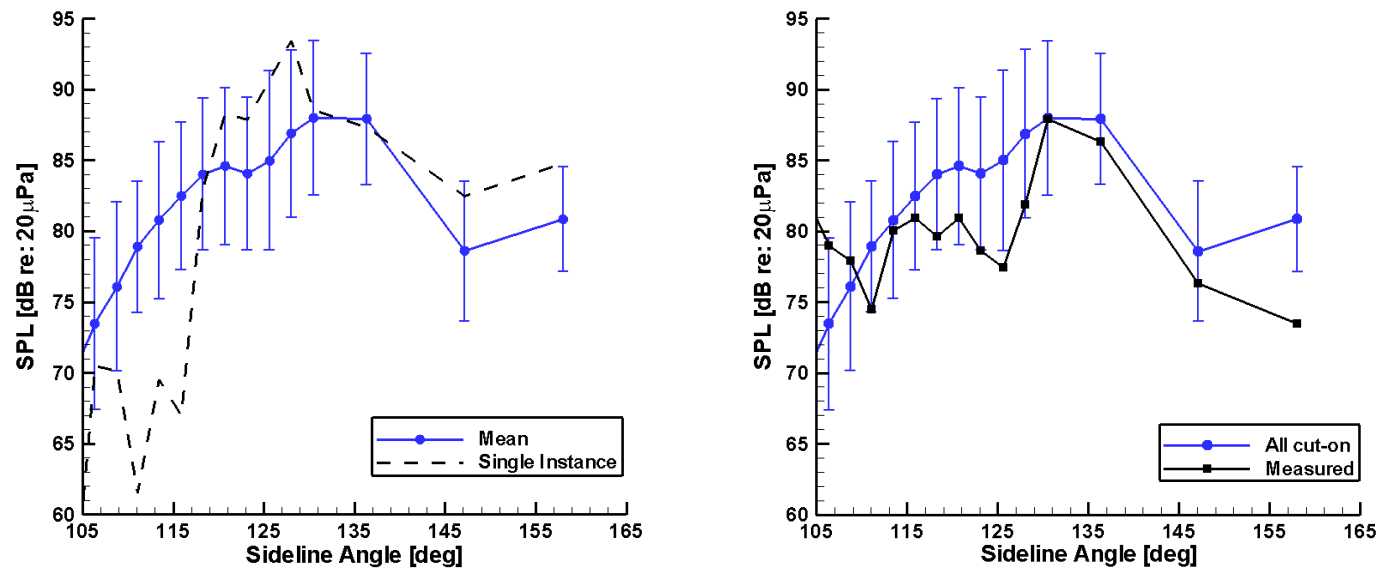

(c) All cut-on modes

Figure 15: 2xBPF exhaust RR/CDUCT-LaRC (randomized phase) predictions and 9'x15' measured data at approach speed. Dashed lines represent the single instances using complete rotating rake data for source specification. Solid lines with square symbols represent 9'x15' measured data. Error bars on predicted quantities denote a range of $\pm \sigma$. Note that the predictions include the 'pseudo-duct' to model shear layer effects. 